\title{
USO DE CERA E 1-METILCICLOPROPENO NA CONSERVAÇÃO REFRIGERADA DE GRAVIOLA (Annona muricata L.) ${ }^{1}$
}

\author{
MARIA AUXILIADORA COÊLHO DE LIMA², RICARDO ELESBÃO ALVES ${ }^{3}$, HELOÍSA ALMEIDA CUNHA \\ FILGUEIRAS ${ }^{3}$, JOSÉ ROBSON GURGEL LIMA ${ }^{4}$
}

\begin{abstract}
RESUMO - Graviolas 'Morada', provenientes de pomar comercial localizado em Limoeiro do Norte, Ceará, foram colhidas na maturidade fisiológica com o objetivo de avaliar o efeito da aplicação pós-colheita de 1-meticiclopropeno (1-MCP) e cera na conservação, durante o armazenamento

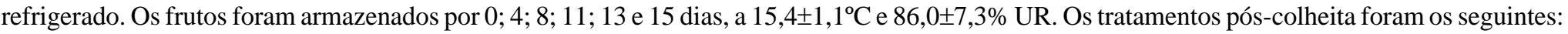
controle, $200 \mathrm{~nL} \mathrm{~L}^{-1}$ de 1-MCP (SmartFresh ${ }^{\top \mathrm{M}}$ ), pulverização com a cera Fruit wax ${ }^{\circledR}$ e pulverização com Fruit wax ${ }^{\circledR}$ seguida de aplicação de $200 \mathrm{~nL}$ $\mathrm{L}^{-1}$ de 1-MCP. O delineamento experimental foi o inteiramente casualizado, em fatorial 4x6 (tratamentos pós-colheita x tempo de armazenamento), com quatro repetições. As variáveis analisadas foram: cor da casca e da polpa, a partir da luminosidade $(\mathrm{L})$, cromaticidade $(\mathrm{C})$ e ângulo de cor $\left(\mathrm{H}^{\circ}\right)$; perda de massa; $\mathrm{pH}$; acidez titulável (AT); sólidos solúveis totais (SST); açúcares solúveis totais (AST) e açúcares redutores (AR). Os tratamentos cera e cera+1-MCP mantiveram estáveis os valores de L da casca e da polpa até o $8^{\circ}$ e o $4^{\circ}$ dia de armazenamento, respectivamente. O aumento em SST foi temporariamente atrasado pelos tratamentos pós-colheita. AAT, pH, AST e AR não foram influenciados pela cera e pelo 1-MCP. O uso da cera diminuiu a perda de massa em $23 \%$, quando comparado ao controle.
\end{abstract}

Termos para Indexação: 1-metilciclopropeno, anonáceas, armazenamento, cera, conservação pós-colheita, qualidade do fruto.

\section{THE OUSE OF WAX AND 1-METHYLCYCLOPROPENE ON REFRIGERATED STORAGE OF SOURSOP FRUIT (Annona muricata L.)}

\begin{abstract}
Fruits of soursop 'Morada' from plants of a commercial area, located in Limoeiro do Norte, Ceara State, Brazil, were harvested at the physiological maturity stage with the objective of evaluating the effect of postharvest application of 1-methylcyclopropene (1-MCP) and wax on conservation during refrigerated storage. Fruits were stored for $0,4,8,11,13$ and 15 days under $15.4 \pm 1.1^{\circ} \mathrm{C}$ and $86.0 \pm 7.3 \%$ RH. Postharvest treatments were as follow: control, $200 \mathrm{~nL} \mathrm{~L}^{-1}$ of 1-MCP (SmartFresh ${ }^{\mathrm{TM}}$ ), Fruit wax ${ }^{\circledR}$ sprayed on fruits, and Fruit wax ${ }^{\circledR}$ sprayed on fruits followed by application of $200 \mathrm{~nL} \mathrm{~L}^{-1}$ of 1-MCP. The experimental design was completely randomized, with a 4x6 (postharvest treatment $\mathrm{x}$ storage time) factorial and four replicates. The following variables were evaluated: skin and pulp color according to luminosity $(\mathrm{L})$, chromaticity $(\mathrm{C})$ and color angle $\left(\mathrm{H}^{\circ}\right)$; mass loss; $\mathrm{pH}$; titratable acidity (TA); total soluble solids (TSS); total soluble sugars (TS) and reducing sugars (RS). Wax and wax $+1-\mathrm{MCP}$ kept stabilized the L values for skin and pulp, until the $8^{\text {th }}$ and the $4^{\text {th }}$ day of storage, respectively. The increasing in TSS was temporarily delayed by postharvest treatments. The TA, pH, TS and RS were not influenced by wax and 1-MCP. The use of wax reduced the mass loss in $23 \%$ compared to the control.
\end{abstract}

Index Terms: 1-methylcyclopropene, anonaceae, storage, wax, postharvest conservation, fruit quality.

\section{INTRODUÇÃO}

A graviola (Annona muricata L.) é um fruto perecível que, em temperatura ambiente e quando colhida na maturidade fisiológica, completa o amadurecimento em até seis dias. Esse comportamento tem sido atribuído ao padrão respiratório climatérico do fruto, caracterizado por mais de um ponto máximo (Paull, 1982).

O crescimento do consumo in natura, em especial nos mercados de São Paulo, Rio de Janeiro, Recife, Salvador, Fortaleza e Brasília (SãoJosé et al., 2000), reforça a necessidade do emprego de tecnologias que retardem o amadurecimento, aumentando a vida útil pós-colheita.

Dentre os métodos de conservação, a refrigeração é o mais utilizado para o armazenamento de frutos e hortaliças. Com a redução da temperatura, a atividade de enzimas envolvidas nas reações de síntese e degradação após a colheita diminui (Wills et al., 1998). Os poucos estudos realizados com graviola relatam que a refrigeração aumenta o período de conservação. Graviolas armazenadas a $15^{\circ} \mathrm{C}$ atingiram características apropriadas para consumo em nove dias (Mosca, 1996). Porém, quando mantidas a $12^{\circ} \mathrm{C} \mathrm{e} 14^{\circ} \mathrm{C}$, graviolas apresentavam aparência imprópria à comercialização aos seis dias (Silva et al., 2001).

Algumas técnicas são comumente associadas à refrigeração, como o recobrimento com ceras especiais. As ceras, além de atuarem como barreiras à transmissão de vapor de água e gases (Hagenmaier, 2000), formam uma camada mais espessa na casca dos frutos (Amarante et al., 2001), o que possibilita reduzir a perda de massa (Hagenmaier, 2000; Xu et al., 2001). Além disso, podem modificar a atmosfera no interior do fruto, reduzindo o metabolismo (Kader, 1995; Wills et al., 1998).

Alguns estudos têm sido feitos com graviola, como o emprego de filmes plásticos (Silva et al., 2001) e película de ésteres de açúcares e ácidos graxos (Guerra et al., 1995).

$\mathrm{O}$ amadurecimento pode ser atrasado, ainda, por meio do uso de inibidores da ação do etileno (Wills et al., 1998), entre os quais se destaca o 1-metilciclopropeno (1-MCP). O 1-MCP compete com o etileno pelos sítios de ligação nos receptores das membranas (Sisler \& Serek, 1997), podendo atrasar ou inibir eventos do amadurecimento dependentes daquele fitormônio (Jiang et al., 1999).

A eficiência do 1-MCP tem sido relatada na retenção da firmeza e cor, na redução e/ou atraso na atividade respiratória e produção de etileno e na redução da incidência de desordens fisiológicas (Fan et al., 1999; Jiang et al., 1999; Watkins et al., 2000; Hofman et al., 2001; Selvarajah et al., 2001).

O objetivo deste estudo foi avaliar o efeito da aplicação póscolheita de 1-MCP e cera na conservação da graviola, durante o armazenamento refrigerado.

\section{MATERIALEMÉTODOS}

Graviolas 'Morada' foram obtidas em plantio comercial, situado em Limoeiro do Norte, Ceará. Os frutos foram colhidos na maturidade fisiológica (identificada através da maior separação entre as terminações estilares, que começavam a perder consistência) e submetidos à aplicação de $300 \mu \mathrm{L} \mathrm{L}^{-1}$ do fungicida Prochloraz, via imersão, durante 3 minutos.

\footnotetext{
${ }^{1}$ (Trabalho 173/2003) Recebido: 21/11/2003. Aceito para publicação: 13/08/2004. Parte da tese de doutorado do primeiro autor apresentada à Universidade Federal do Ceará (UFC).

${ }^{2}$ Dra., Pesquisadora, Embrapa Semi-Árido, CP 23, 56.300-970, Petrolina-PE. maclima@ cpatsa.embrapa.br. 87 3862-1711 ramal 254

${ }^{3}$ Dr., Bolsista PQ/CNPq, Pesquisador, Embrapa Agroindústria Tropical, CP 3761, 60.511-110, Fortaleza-CE. elesbao@ cnpat.embrapa.br, heloisa@cnpat.embrapa.br. $85299-1847$

${ }^{4}$ Estudante de Química Industrial, Estagiário, Embrapa Agroindústria Tropical, CP 3761, 60.511-110, Fortaleza-CE.
} 
Foram avaliados tratamentos pós-colheita e tempo de armazenamento. Os tratamentos pós-colheita utilizados foram: 1. controle 2. aplicação de $200 \mathrm{~nL} \mathrm{~L}^{-1}$ de 1-metilciclopropeno (1-MCP), a partir do produto comercial SmartFresh ${ }^{\mathrm{TM}}(0,14 \%$ i.a.); 3 . pulverização com a cera Fruit wax ${ }^{\circledR}$, constituída de emulsão de polietileno, resina fumárica, preservante e água; 4. pulverização com Fruit wax ${ }^{\circledR}$ seguida da aplicação de $200 \mathrm{~nL} \mathrm{~L}^{-1}$ de $1-\mathrm{MCP}$

Para a aplicação do 1-MCP, os frutos foram acondicionados em câmaras herméticas e expostos ao produto por 12 horas sob temperatura de $15,4 \pm 1,1^{\circ} \mathrm{C}$ e umidade relativa de $86,0 \pm 7,3 \%$. Após o tratamento, os frutos permaneceram nas mesmas condições de temperatura e umidade relativa. As avaliações foram realizadas aos $0 ; 4 ; 8 ; 11 ; 13$ e 15 dias.

As variáveis analisadas foram: a) Cor da casca e da polpa: determinadas com reflectômetro e os resultados expressos em luminosidade (L), cromaticidade (C) e ângulo de cor $\left(\mathrm{H}^{\circ}\right)$. Para a cor da casca, foram realizadas duas leituras por fruto, em lados opostos da região equatorial e na base das terminações estilares. Para a cor da polpa, as duas leituras foram realizadas na região equatorial da metade longitudinal do fruto, nos lados direito e esquerdo, eqüidistantes do centro; b) Perda de massa (\%): obtida através da massa do fruto no dia da colheita e na data da avaliação, utilizando balança semi-analítica; c) pH: obtido em potenciômetro digital (IAL, 1985); d) Acidez titulável (AT, \% de ácido málico): determinada por titulação com solução de $\mathrm{NaOH} 0,1$ M até o pH 8,1, conforme metodologia do IAL (1985); e) Sólidos solúveis totais (SST, ${ }^{\circ}$ Brix): determinados por leitura em refratômetro digital (IAL, 1985); f) Açúcares solúveis totais (AST, \%): extraídos em álcool 80\% e determinados segundo Yemn \& Willis (1954); g) Açúcares redutores (AR, \%): a extração foi feita em água, e a determinação realizada segundo Miller(1959).

O delineamento experimental foi o inteiramente casualizado, em fatorial 4x6, com quatro repetições, exceto os tratamentos 1-MCP e 1$\mathrm{MCP}+$ cera, avaliados aos quatro dias, que tiveram uma parcela perdida. Cada parcela foi constituída por um fruto.

Os dados foram submetidos à análise de variância e de regressão polinomial. Quando houve efeito significativo da interação, realizou-se o desdobramento de tratamentos pós-colheita em cada tempo de armazenamento.

Os valores de perda de massa foram analisados após transformação em arc-sen $\sqrt{\frac{x}{100}}$. Para representação gráfica, utilizou-se das médias obtidas com a operação inversa à transformação.

\section{RESULTADOSEDISCUSSÃO}

Dentre os atributos da cor da casca, somente a luminosidade (L) foi influenciada pelos tratamentos pós-colheita durante o armazenamento (Tabela 1). Nos frutos-controle, houve decréscimo constante na L. Nos frutos tratados com cera e cera+1-MCP, a L diminuiu até $\mathrm{o} 4^{\circ}$. dia de armazenamento, mantendo-se estável até o $11^{\circ}$. dia. Para os frutos tratados com 1-MCP, a redução da L da casca só foi verificada após oito dias (Figura 1A).

Períodos de aumento na $\mathrm{L}$ da casca, como observado no tratamento cera+1-MCP, a partir do $11^{\circ}$ dia, ou nos tratamentos em que se aplicou apenas cera ou 1-MCP, aos 8 e 13 dias, respectivamente (Figura 1A), apesar de dificultarem uma caracterização mais precisa dessa variável, sugerem que nos momentos citados houve melhoria da aparência da graviola através do incremento no brilho superficial.

Entretanto, essa resposta nem sempre é observada. A variabilidade natural da espécie é um fator que tem influenciado nestas diferenças, limitando, portanto, o uso da cor como indicador de maturidade em graviola (Lima et al., 2003). Em condição de temperatura ambiente, os autores não observaram diferença estatisticamente significativa na $L$ da casca, durante a maturação pós-colheita da graviola 'Morada'.

As variações na cromaticidade $(C)$ e no ângulo de cor $\left(\mathrm{H}^{\circ}\right)$ da casca, por sua vez, não foram influenciadas pelos tratamentos póscolheita (Tabela 1). A C, que representa a intensidade da cor, aumentou até $\mathrm{o} 8^{\circ}$. dia de armazenamento, seguida por leve decréscimo (Figura 1B). É possível que esse decréscimo esteja associado ao início de escurecimento da casca decorrente do avanço do amadurecimento da graviola e sua posterior senescência.

$\mathrm{O}$ decréscimo no $\mathrm{H}^{\circ}$, ao longo do período de armazenamento, indica o amarelecimento da casca (Figura 1B). A resposta concorda com os resultados obtidos por Lima et al. (2003), podendo estar associada à degradação da clorofila.

Paull (1982) relatou que a cor da casca da graviola muda de verde-escuro para uma cor mais amarelada durante o amadurecimento, tendendo a tornar-se completamente escura com a senescência. No entanto, segundo Wills et al. (1984), as mudanças podem ser tão pequenas que não se tornam visíveis

No que se refere ao efeito de tratamentos pós-colheita sobre a cor, os resultados têm sido divergentes. O 1-MCP tem se mostrado efetivo em atrasar as mudanças na cor de alguns frutos, como abacaxi (Selvarajah et al., 2001) e manga (Hofman et al., 2001). Mas existem situações em que não se verifica o efeito ou as respostas variam dependendo, por exemplo, do estádio de maturação, do tempo de exposição ao produto e da temperatura de armazenamento (Pelayo et al., 2003). Segundo os autores, deve-se considerar também que efeitos de menor intensidade podem ser mascarados pela variabilidade entre frutos.

Wills et al. (1998) ressaltam que as mudanças na cor podem ser dependentes de etileno. Assim, tratamentos que afetam o metabolismo deste fitormônio, podem ter respostas diferentes quanto a modificações na cor durante o amadurecimento.

Os efeitos dos fatores estudados sobre a cor da polpa foram semelhantes aos obtidos para a cor da casca. Os frutos-controle tiveram redução gradual na L da polpa (Figura 1C). Naqueles tratados com 1$\mathrm{MCP}$, a redução também foi linear. Contudo o valor alcançado aos quinze dias foi ligeiramente superior aos demais. A aplicação de cera, isolada ou em combinação com 1-MCP, reteve mudanças na $L$ da polpa até o $4^{\circ}$. dia de armazenamento. A partir daí, verificou-se redução na $L$, que foi mais

TABELA 1 - Significância do teste F da análise de variância para os efeitos dos tratamentos pós-colheita e do período de armazenamento sobre as variáveis luminosidade $(\mathrm{L})$, cromaticidade $(\mathrm{C})$ e ângulo de cor $\left(\mathrm{H}^{\circ}\right)$ da casca e da polpa, perda de massa (PM), $\mathrm{pH}$, acidez titulável (AT), sólidos solúveis totais (SST), açúcares solúveis totais (AST) e açúcares redutores (AR) de graviola 'Morada' armazenada sob refrigeração $\left(15,4 \pm 1,1^{\circ} \mathrm{C}\right.$ e $86,0 \pm 7,3 \%$ UR).

\begin{tabular}{|c|c|c|c|c|c|c|c|c|c|c|c|c|}
\hline Tratamentos e Interação & L casca & C casca & $\mathrm{H}^{\mathrm{o}}$ casca & L polpa & C polpa & $\mathrm{H}^{\mathrm{o}}$ polpa & PM & $\mathrm{pH}$ & AT & SST & AST & AR \\
\hline & \multicolumn{12}{|c|}{ 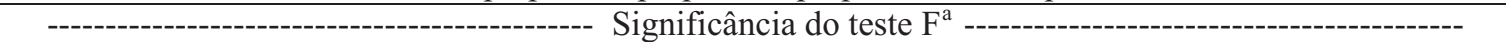 } \\
\hline Tempo de armazenamento $(\mathrm{A})^{\mathrm{b}}$ & $\mathrm{ns}$ & $* *$ & ** & $* *$ & * & * & $* *$ & $* *$ & $* *$ & $* *$ & $* *$ & $* *$ \\
\hline Tratamentos pós-colheita $(\mathrm{P})^{\mathrm{c}}$ & * & ns & ns & ns & ns & ns & $* *$ & ns & ns & ns & ns & ns \\
\hline $\mathrm{A} \times \mathrm{P}$ & $*$ & ns & ns & * & ns & ns & $* *$ & ns & ns & * & ns & ns \\
\hline Coeficientes de variação (\%) & 7,0 & 19,3 & 4,9 & 3,3 & 20,6 & 2,3 & 9,2 & 5,9 & 18,4 & 9,2 & 12,2 & 13,0 \\
\hline
\end{tabular}

${ }^{a}$ ns=não significativo, ${ }^{*}=$ significativo ao nível de $5 \%$ de probabilidade e $* *=$ significativo ao nível de $1 \%$ de probabilidade.

b Tempo de armazenamento $=0 ; 4 ; 8 ; 11 ; 13$ e 15 dias

Tratamentos pós-colheita = controle, aplicação de 200 nL L ${ }^{-1}$ de 1-MCP, pulverização com a cera Fruit wax ${ }^{\circledR}$ e pulverização com Fruit wax ${ }^{\circledR}$ seguida da aplicação de $200 \mathrm{~nL} \mathrm{~L}^{-1}$ de $1-\mathrm{MCP}$ 


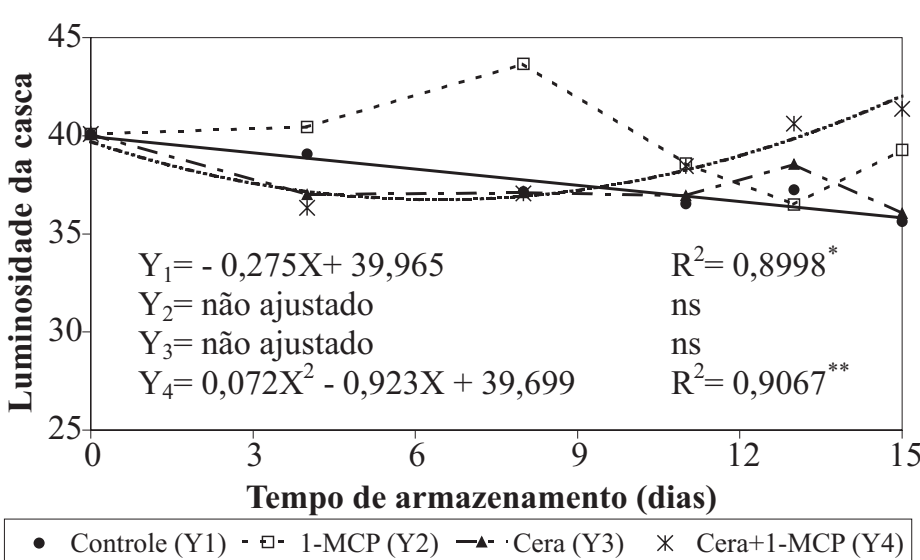

Controle (Y1) - ঘ- 1-MCP (Y2) -^- Cera (Y3) $\quad *$ Cera+1-MCP (Y4)

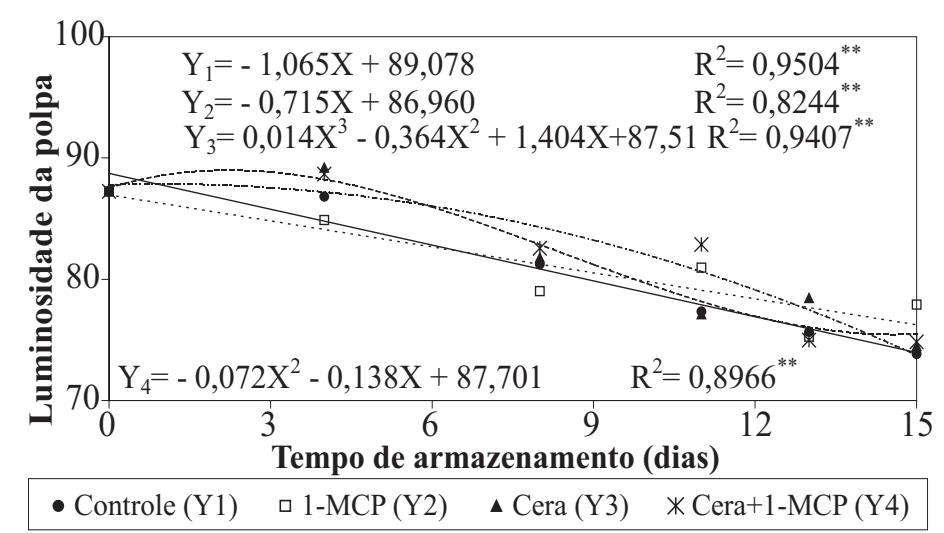





FIGURA 1 - Luminosidade (A), cromaticidade e ângulo de cor (B) da casca e luminosidade (C), cromaticidade e ângulo de cor (D) da polpa de graviola

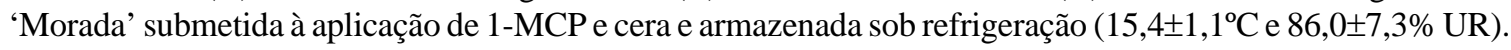

lenta nos frutos tratados com cera+1-MCP.

É possível que a cera, limitando a transmissão de gases através da epiderme, tenha promovido elevação do teor de $\mathrm{CO}_{2}$ e redução do teor de $\mathrm{O}_{2}$ no interior do fruto (Amarante et al., 2001). Como conseqüência, a velocidade de alguns eventos metabólicos, como mudanças na cor da polpa, pode ter sido reduzida.

As alterações na $\mathrm{C}$ e no $\mathrm{H}^{\circ}$ da polpa foram pouco representativas e sofreram influência apenas do tempo de armazenamento (Figura 1D). A resposta concorda com a afirmação de Lima et al. (2003) de que o amadurecimento da graviola não envolve mudanças expressivas na cor da polpa, sendo determinada apenas pela $\mathrm{L}$.

A aplicação da cera reduziu a perda de massa da graviola durante o armazenamento, especialmente do $8^{\circ}$ ao $13^{\circ}$ dia (Figura 2A). No final do período de armazenamento, observou-se que os frutos dos tratamentoscontrole, 1-MCP, cera e cera+1-MCP tiveram perda de massa de 10,22; 8,$50 ; 7,90$ e $8,61 \%$, respectivamente. Nessa ocasião, a perda de massa dos frutos tratados apenas com 1-MCP equivaleu à dos frutos que receberam cera. No entanto, até o $13^{\circ}$ dia, os valores foram comparáveis ao do controle, não sendo esse tratamento eficiente na limitação da perda de massa do fruto.

Deve-se ressaltar que, mesmo nos frutos que apresentaram perda de massa superior a 10\%, não foram observados sinais de murcha (dados não apresentados).

Em graviola, Guerra et al. (1995) avaliaram o uso de película de ésteres de açúcares e de ácidos graxos, durante o armazenamento a $16^{\circ}$ C. Porém, os frutos não amadureceram, provavelmente, por não terem atingido a maturidade mínima para a colheita, o que limitou a avaliação da eficiência do tratamento.

O efeito das ceras na limitação da perda de massa é esperado na maioria dos casos. As ceras mantêm a aparência de alguns frutos, uma vez que podem preservar o brilho da superfície como consequiência da reduzida perda de massa (Hagenmaier, 2000; Xu et al., 2001) e prevenir danos causados por fricção e que causam descoloração superficial (Amarante et al., 2001).
A acidez titulável (AT) aumentou, durante o período de armazenamento, independentemente do tratamento pós-colheita (Figura 2B). A partir do $8^{\circ}$. dia, a AT manteve-se estável em torno de $0,8 \%$ de ácido málico, apresentando pequeno decréscimo no final do período de armazenamento. É possível que esta redução indique a utilização dos ácidos orgânicos como substrato para a respiração. Paull (1982) observou que, sob temperatura ambiente, a diminuição na AT da graviola coincidia com o aparecimento de odor levemente desagradável. Portanto, a referida diminuição pode ser usada como indicativo de senescência.

Poucos frutos têm aumento na AT com o progresso do amadurecimento (Wills et al., 1998). Além da graviola, a atemóia (Wills et al., 1984) e o kiwi (Xu et al., 2001) são outros exemplos.

Em alguns casos, o uso de ceras ou outras formulações para recobrimento de frutos (Xu et al., 2001) ou do 1-MCP (Watkins et al., 2000) pode atrasar a evolução da AT. Em outros, as diferenças podem não ser detectadas (Kluge et al., 1999).

$\mathrm{O}$ pH, em concordância com a AT, decresceu até o $8^{\circ}$. dia, mantendo-se estável até o final do armazenamento, quando foi observado leve aumento (Figura 2B).

O aumento no teor de sólidos solúveis totais (SST), decorrente do amadurecimento, foi temporariamente atrasado pelos tratamentos 1MCP, cera e cera+1-MCP (Figura 2C). Aos treze dias, quando os frutos ainda não haviam iniciado a senescência, conforme indicado pela AT (Figura 2B), os tratamentos-controle, 1-MCP, cera e cera+1-MCP tiveram valores de SST de 15,0;14,2;14,4 e 13,6 ${ }^{\circ}$ Brix, respectivamente.

O 1-MCP não exerce efeito sobre o teor de SST em atemóia, mamão, manga (Hofman et al., 2001) e maçã (Watkins et al., 2000). Hofman et al. (2001) sugeriram que, provavelmente, o efeito do 1-MCP nas características associadas ao sabor, como teor de SST e AT, seja pouco significativo. Segundo Fan et al. (1999), isto indicaria que, naqueles frutos, a percepção do etileno não está, necessariamente, envolvida no acúmulo de SST. O mesmo não pode ser afirmado para abacaxi (Selvarajah et al., 2001), que acumulou menos SST quando tratado com 1-MCP.

Os teores de açúcares solúveis totais (AST) e redutores (AR) 


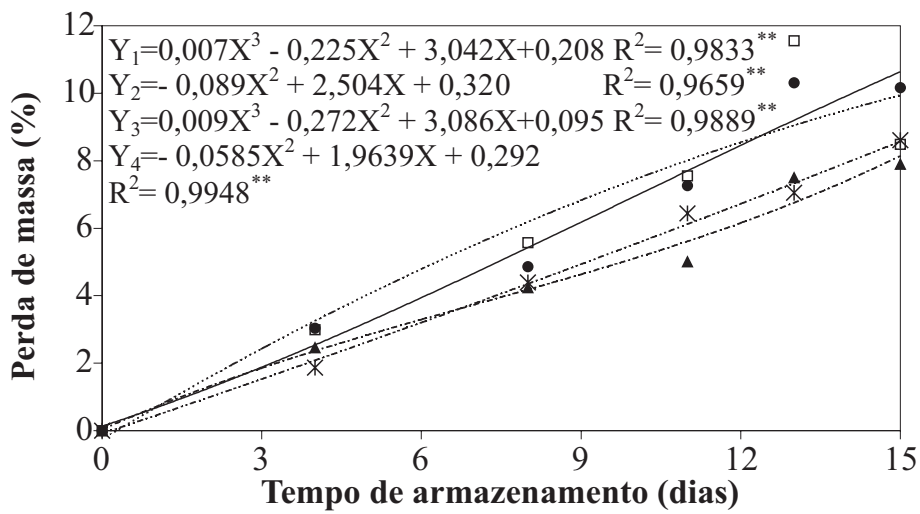

- Controle (Y1) ฉ 1-MCP (Y2) ^ Cera (Y3) $*$ Cera+1-MCP (Y4)



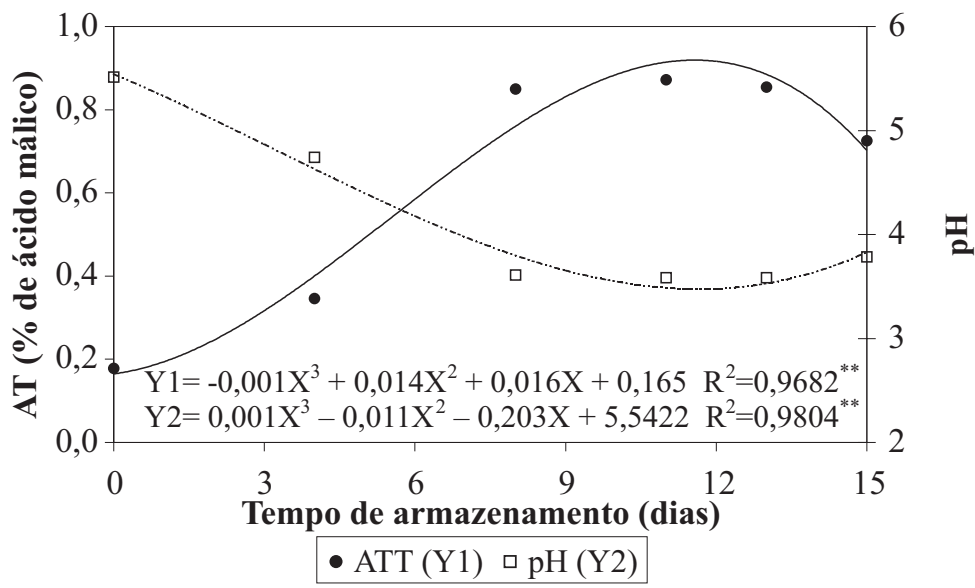

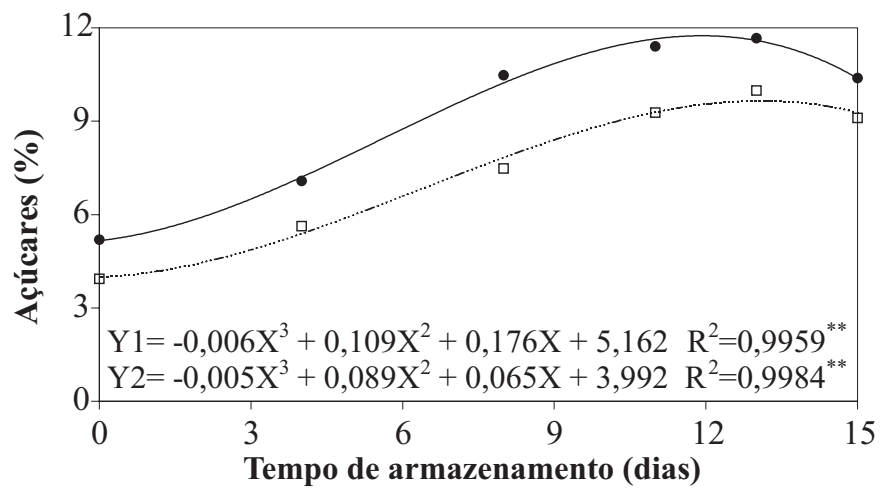

- AST (Y1) व AR (Y2)

FIGURA 2 - Perda de massa (A), acidez titulável (AT), pH (B), teor de sólidos solúveis totais (SST) (C), teor de açúcares solúveis totais (AST) e de açúcares redutores $(\mathrm{AR})(\mathbf{D})$ de graviola 'Morada' submetida à aplicação de 1-MCP e cera e armazenada sob refrigeração $\left(15,4 \pm 1,1^{\circ} \mathrm{C}\right.$ e $86,0 \pm 7,3 \%$ UR).

aumentaram a uma taxa semelhante durante o armazenamento, sem que fossem influenciados pelos tratamentos pós-colheita (Figura 2D e Tabela 1). Os maiores teores de AST e AR foram observados aos treze dias de armazenamento e corresponderam a 11,67 e 9,99\%, respectivamente, comportamento semelhante ao teor de SST (Figura 2C).

A inexistência de resposta do emprego da AM sobre os teores de AST, principal componente dos SST, e AR concorda com relatos de $\mathrm{Xu}$ et al. (2001). Os autores ressaltam que apenas quando os níveis de oxigênio são reduzidos a valores que limitam a respiração aeróbica, o acúmulo de SST e, conseqüentemente, de açúcares durante o armazenamento é restringido.

\section{CONCLUSÕES}

1) A aplicação de cera à base de polietileno em graviola 'Morada' é uma técnica viável que, associada à refrigeração, reduz a perda de massa.

2) A aplicação de $200 \mathrm{~nL} \mathrm{~L}^{-1}$ de 1-MCP, isoladamente, não representa incremento na conservação pós-colheita da graviola 'Morada', sob refrigeração.

\section{REFERÊNCIAS}

AMARANTE, C.; BANKS, N.; GANESH, S. Effects of coating concentration, ripening stage, water status and fruit temperature on pear susceptibility at friction discolouration. Postharvest Biology and Technology, Amsterdam, v.21, n.3, p.283-290, 2001.

FAN, X.; BLANKENSHIP, S.M.; MATTHEIS, J.P. 1-Methylcyclopropene inhibits apple ripening. Journal of the American Society for Horticultural Science, Alexandria, v.124, n.6, p.690-695, 1999.

GUERRA, N.B.; BACHMANN, C.; MELO FILHO, A.B. de. Influência do tempo de estocagem sobre a qualidade de graviolas (Annona muricata L.) revestidas com "SemperFresh". In: CONGRESSO
BRASILEIRODE FRUTICULTURA, 13., 1995, Salvador. Resumos... Salvador: SBF, 1995. v.2, p.601-602.

HAGENMAIER, R.D. Evaluation of a polyethylene-candelilla coating for 'Valencia' oranges. Postharvest Biology and Technology, Amsterdam, v.19, n.2, p.147-154, 2000.

HOFMAN, P.J.; JOBIN-DECOR, M.; MEIBURG, G.F.; MACNISH, A.J.; JOYCE, D.C. Ripening and quality responses of avocado, custard apple, mango and papaya fruit to 1-methylcyclopropene. Australian Journal of Experimental Agriculture, Victoria, v.41, p.567-572, 2001.

INSTITUTO ADOLFO LUTZ. Normas analíticas, métodos químicos e físicos para análise de alimentos. São Paulo: IAL, 1985. v.1, 371p.

JIANG, Y.; JOYCE, D.C.; MACNISH, A. Responses of banana fruit treatment with 1-methylcylcopropene. Journal of Plant Growth Regulation, Dordrecht, v.28, p.77-82, 1999.

KADER, A.A. Regulation on fruit physiology by controlled/modified atmospheres. Acta Horticulturae, Kyoto, n.398, p.81-91, 1995

KLUGE, R.A.; BILHALVA, A.B.; CANTILLANO, R.F.F. Influência do estádio de maturação e da embalagem de polietileno na frigoconservação de ameixa. Pesquisa Agropecuária Brasileira, Brasília, v.34, n.3, p.323-329, 1999.

LIMA, M.A.C. de; ALVES, R.E.; FILGUEIRAS, H.A.C.; ENÉAS-FILHO, J. Comportamento respiratório e qualidade pós-colheita de graviola (Annona muricata L.) 'Morada' sob temperatura ambiente. Revista Brasileira de Fruticultura, Jaboticabal, v.25, n.1, p.49-52, 2003.

MILLER, G.L. Use of dinitrosalicylic acid reagent for determination of reducing sugars. Analytical Chemistry, Washington, v.31, n.3, p.426$428,1959$.

MOSCA, J.L. Estudos de maturação e práticas pós-colheita para conservação de frutos de anonáceas in natura. Fortaleza: EMBRAPA-CNPAT, 1996. 6p. (Relatório Técnico Parcial ao FUNDECI/BNB).

PAULL, R.E. Postharvest variation in composition of soursop (Annona muricata L.) fruit in relation to respiration and ethylene production. 
Journal of the American Society for Horticultural Science, Alexandria, v.107, n.4, p.582-585, 1982.

PELAYO, C.; VILAS-BOAS, E.V. de B.; BENICHOU, M.; KADER, A.A. Variability in responses of partially ripe bananas to 1methylcyclopropene. Postharvest Biology and Technology, Amsterdam, v.28, n.1, p.75-85, 2003.

SÃO-JOSÉ, A.R.; ANGEL, D.N.; BOMFIM, M.P.; REBOUÇAS, T.N.H. Cultivo da graviola. In: SEMANA INTERNACIONAL DE FRUTICULTURAEAGROINDÚSTRIA, 7., 2000, Fortaleza. Cursos... Fortaleza: SINDIFRUTA, FRUTAL, 2000. 35p. CD-ROM.

SELVARAJAH, S.; BAUCHOT, A.D.; JOHN, P. Internal browning in coldstored pineapples is suppressed by a postharvest application of 1methylcyclopropene. Postharvest Biology and Technology, Amsterdam, v.23, n.2, p.167-170, 2001.

SILVA, S.M.; MARTINS, L.P.; SANTOS, J.G. dos S.; ALVES, R.E. Conservação pós-colheita de frutos de graviola (Annona muricata L.) sob atmosfera modificada. Revista Iberoamericana de Tecnología Postcosecha, Hermosillo, v.4, n.1, p.6-12. 2001.

SISLER, E.C.; SEREK, M. Inhibitors of ethylene responses in plants at the receptor level: recent developments. Physiologia Plantarum,
Copenhagen, v.100, n.3, p.577-582. 1997.

WATKINS, C.B.; NOCK, J.F.; WHITAKER, B.D. Responses of early, mid and late season apple cultivars to postharvest application of 1methylcyclopropene (1-MCP) under air controlled atmosphere storage conditions. Postharvest Biology and Technology, Amsterdam, v.19, n.1, p.17-32. 2000.

WILLS, R.; MCGLASSON, B.; GRAHAM, D.; JOYCE, D.C. Postharvest: an introduction to the physiology \& handling of fruit, vegetables \& ornamentals. 4th ed. Wallingford: New South Wales University Press, 1998. 262p.

WILLS, R.B.H.; POI, A.; GREENFELD, H.; RIGNEY, C.J. Postharvest changes in fruit composition of Annona atemoya during ripening and effects of storage temperature on ripening. HortScience, Alexandria, v.19, n.1, p.96-97, 1984.

XU, S.; CHEN, X.; SUN, D.W. Preservation of kiwifruit coated with an edible film at ambient temperature. Journal of Food Engineering, Amsterdam, v.50, n.4, p.211-216, 2001.

YEMN, E.W.; WILLIS, A.J. The estimation of carbohydrate in plant extracts by anthrone. Biochemistry Journal, Cambridge, v.57, n.2, p.504-514, 1954. 